\title{
The Influence of the National Health Insurance on Access and Catastrophic Health Expenditures for Patients with Chronic Renal Disease; and the Possibility of Integrating Organ Transplantation in Laos' Health Financing System.
}

SOMDETH Bodhisane ( $\nabla$ somdethb@rocketmail.com )

Chulalongkorn University https://orcid.org/0000-0002-1451-6185

Sathirakorn Pongpanich

Chulalongkorn University College of Public Health Sciences

Research

Keywords:

Posted Date: January 18th, 2022

DOI: https://doi.org/10.21203/rs.3.rs-1242270/v1

License: (c) (1) This work is licensed under a Creative Commons Attribution 4.0 International License.

Read Full License 


\section{Abstract}

Laos has difficulties in accessing and obtaining proper health services compared to more developed countries, due to the availability of health facilities and health financing programs. Hemodialysis (HD) is currently under the coverage of the National Health Insurance $(\mathrm{NHI})$. However, there are several technical barriers related to health service utilization. This study aims to carefully analyze the role of Laos' National Health Insurance on issues of accessibility and the possibility of encountering catastrophic health expenditures for chronic kidney disease patients. In addition, this study is also willing to provide policy recommendations for policymakers in offering organ transplantation under $\mathrm{NHI}$ in the future.

The Savannakhet Province is purposively selected as a study site, where 342 respondents participated in the study. Two logistic regression models have been used to assess the effectiveness of the $\mathrm{NHI}$ in terms of accessibility and financial protection against catastrophic health expenditures. This research applies the Anderson Behavioral Model as a guideline to factors that affect accessibility and economic catastrophe.

$\mathrm{NHI}$ improves accessibility to health service utilization for a household with chronic kidney disease. However, due to the limited hemodialysis services, there is a barrier to accessing health services and financial hardship due to non-medical expenditures. Chronic conditions, in addition to kidney issues, dramatically increase the chances of suffering catastrophic health expenditures. In the short run, NHI's policymakers are highly recommended to collaborate with neighboring countries' hospitals through copayment programs. For long-term policy guidelines, the government should move forward to include kidney transplants in the NHI's healthcare system

\section{Background And Rationale}

Laos' health financing system has made remarkable progress towards universal health. The social health protection coverage was rapidly increased from merely $10.5 \%$ in 2008 to over $94 \%$ of the total population in 2018. Health financing in Laos was started when the government introduced the State Authority for Social Security (SASS) scheme, a compulsory plan for government officials, in 1995, followed by the Social Security Organization Scheme (SSO) for formal salaried workers under private enterprises in 2001. In 2002, the voluntary-based health insurance scheme targeting self-employed and informal economy workers was initialized through the initiative of Community-Based Health Insurance (CBHI). In addition, the government also introduced the Health Equity Fund (HEF) in 2004, focusing on the target group of poor and vulnerable people. In this case, the government purchased $\mathrm{CBHI}$ healthcare plans for poor people, certified by the heads of villages or local authorities. Besides, the Free Maternal Neonatal and Child Health (FMNCH) services policy has been implemented to support mother and child health ${ }^{1,2}$. The idea of gathering all related schemes under one umbrella came up in 2012 when the Prime Minister issued the Decree 470/PM to develop the National Health Insurance (NHI) Fund. In 2016, the NHI was officially initialized under the $\mathrm{CBH}, \mathrm{HEF}$, and $\mathrm{FMNCH}$, under the Ministry of Health. In particular, between 2016 to 2017, the scheme was quickly expanded to all 17 provinces except Vientiane Capital, which 
protected informal employment through $\mathrm{CBHI}{ }^{3}$. The timeline of Lao health financing between 1995 to 2016 has been shown in Table 1.

Table 1

Timeline of health financing in Laos

\begin{tabular}{|ccll|}
\hline \multicolumn{2}{|c|}{ Period } & Health financing policy & Source of funding \\
\hline 1 & 1995 & $\begin{array}{l}\text { The State Authority for Social Security (SASS) for civil } \\
\text { servants }\end{array}$ & Salary \\
\hline 2 & 2001 & $\begin{array}{l}\text { The Social Security Organization (SSO) for formal } \\
\text { salaried workers }\end{array}$ & Salary \\
\hline 3 & 2002 & $\begin{array}{l}\text { Community - Based Health Insurance (CBHI) for self- } \\
\text { employed and informal economy workers }\end{array}$ & Contribution rates \\
\hline 4 & 2010 & $\begin{array}{l}\text { Free Maternal Neonatal and Child Health (FMNCH) } \\
\text { services policy }\end{array}$ & Various \\
\hline 5 & 2016 & National Health Insurance $(\mathrm{NHI})$ & $\begin{array}{l}\text { Fixed copayment rates and } \\
\text { government subsidy }\end{array}$ \\
\hline
\end{tabular}


Table 2

Respondents and their household sociodemographic and hospital admission

\section{Respondent's/ household's sociodemographic}

Gender of respondent

Male

Female

Marital status

Single

Married

Age of respondents

$18-35$

$36-49$

50 or above

Level of education

No schooling to lower secondary school

Lower secondary school to secondary

school

College/ university degree

Size of household

1-4 people (small)

5 people or more (large)

Level of income

Less than 1 million LAK (US\$100)

1- 2.5 million LAK (US\$100 - US\$250)

2.5 - 5 million LAK (US\$250 - US\$ 500)

More than 5 million LAK (US\$500)

Respondents' occupation

Business owner

Farmer

Street vendor
Hospital admission

No Yes Total

112

$(58.6 \%)$

$79(41.4 \%)$

$58(30.4 \%)$

133

$(69.6 \%)$

$46(24.1 \%)$

99 (51.8\%)

$46(24.1 \%)$

$22(11.5 \%)$

106

$(55.5 \%)$

$63(33 \%)$

$105(55 \%)$

$86(45 \%)$

$41(21.5 \%)$

40 (20.9\%)

$72(37.7 \%)$

38 (19.9\%)

$20(10.5 \%)$

50

(26.25\%)

$48(25.1 \%)$

$48(25.1 \%)$

25 (13.1)

109

(57.1\%)

$82(42.9 \%)$

155

(81.2\%)

Page 4/23

$84(55.6 \%) \quad 200$

$67(44.4 \%)$

104

$34(22.5 \%) \quad(30.4 \%)$

$30(19.9 \%) \quad 189$

$58(38.4 \%)$

153

20 (13.2\%) 75 (21.9\%)

$41(27.2 \%) \quad 130(38 \%)$

$34(22.5 \%)$

$91(60.3 \%) \quad 86(25.1 \%)$

$60(39.7 \%) \quad 89(26.0 \%)$

119

(78.8\%)

$32(21.2 \%)$
Pearson

$\mathrm{X}^{2}$

0.507

$(60.2 \%)$

0.906

136

$47(31.1 \%) \quad(39.8 \%) \quad 0.01$ *

104

$(68.9 \%)$

$13(8.6 \%)$

$15(9.9 \%)$

123

$(81.5 \%)$

$16(10.6 \%)$

$94(62.3 \%)$

$41(27.2 \%) \quad 38(11.1 \%)$

169

(33.3\%)

105
$(30.7 \%)$

237

$(69.3 \%)$

0.435

0.913

0.989

$59(17.3 \%) \quad 0.892$

0.582

0.589

(49.4\%)

$(58.5 \%)$

$(53.3 \%)$

$(44.7 \%)$

$36(23.8 \%) \quad 70(20.5 \%)$

$67(19.6 \%)$

$20(13.2 \%) \quad 40(11.7 \%)$

$82(24.0 \%)$

$45(13.2 \%)$ 


\begin{tabular}{|c|c|c|c|c|}
\hline \multirow{2}{*}{$\begin{array}{l}\text { Respondent's/ household's } \\
\text { sociodemographic }\end{array}$} & \multicolumn{3}{|c|}{ Rospital àdmission } & \multirow{2}{*}{$\begin{array}{l}\text { Pearson } \\
X^{2}\end{array}$} \\
\hline & No & Yes & Total & \\
\hline Laborer & & & $\begin{array}{l}200 \\
(58.5 \%)\end{array}$ & \\
\hline Government official & & & & \\
\hline City of residence & & & $(41.5 \%)$ & \\
\hline Capital (Kaysone Phomvihane district) & & & $\begin{array}{l}274 \\
(80.1 \%)\end{array}$ & \\
\hline Others & & & $68(19.9 \%)$ & \\
\hline Chronic condition & & & & \\
\hline No & & & & \\
\hline Yes & & & & \\
\hline
\end{tabular}


Table 3

Respondents and their household sociodemographic and catastrophic health expenditure

\section{Respondent's/ household's sociodemographic}

Gender of respondent

Male

Female

Marital status

Single

Married

Age of respondents

$18-35$

36-49

50 or above

Level of education

Primary school

Lower secondary school to secondary

school

College/ university degree

Size of household

1-4 people (small)

5 people or more (large)

Level of income

Less than 1 million LAK (US\$100)

1- 2.5 million LAK (US\$100 - US\$250)

2.5 - 5 million LAK (US\$250 - US\$ 500)

More than 5 million LAK (US\$500)

Respondents' occupation

Business owner

Farmer

Street vendor
Catastrophic Health expenditure

No

110

$(56.4 \%)$

$85(43.6 \%)$

$56(28.7 \%)$

139

(73.7\%)

38 (19.5\%)

67 (34.4\%)

$90(46.2 \%)$

$16(8.2 \%)$

140

(71.8\%)

39 (20\%)

100

(51.3\%)

$95(48.7 \%)$

11 (5.6\%)

$26(13.3 \%)$

99 (50.8\%)

59 (30.3\%)

33 (16.9\%)

37 (19.0\%)

51 (26.2\%)

$42(21.5 \%)$

32 (16.4\%)

132

(67.7\%)

63 (32.3\%)

190

(97.4\%)
Yes

96

(65.3\%)

51

(34.7\%)

49

(33.3\%)

98

(66.7\%)

21

(14.3\%)

47 (32\%)

79

(53.7\%)

22 (15\%) 38 (11.1\%)

$60 \quad 200$

(40.8\%) (58.5\%)

65

(44.2\%)

89

$(60.5 \%)$

58

(39.5\%) (44.7\%)

64

$(43.5 \%)$

44

$(29.9 \%)$

31

(21.1\%) $67(19.6 \%)$

$8(5.4 \%) \quad 40(11.7 \%)$

$7(4.8 \%) \quad 86(25.1 \%)$

49

(33.3\%)

38

(25.9\%) $\quad 45(13.2 \%)$
Pearson

$\mathrm{X}^{2}$

0.118

0.407

0.296

0.00 *

0.088

$0.001^{*}$

0.001 *

$0.001^{*}$

$0.001^{*}$ 


\begin{tabular}{|c|c|c|c|c|}
\hline \multirow{2}{*}{ 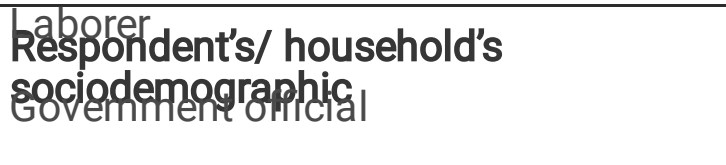 } & \multicolumn{3}{|c|}{ Catastrophic Health expenditure } & \multirow{2}{*}{$\begin{array}{l}\text { Pearson } \\
X^{2}\end{array}$} \\
\hline & No & Yes & Total & \\
\hline City of resident & & \multirow{2}{*}{$\begin{array}{l}40 \\
(27.2 \%)\end{array}$} & \multirow{2}{*}{$\begin{array}{l}200 \\
(58.5 \%)\end{array}$} & \\
\hline \multirow{2}{*}{ Others } & & & & \\
\hline & & $13(8.8 \%)$ & $\begin{array}{l}142 \\
(41.5 \%)\end{array}$ & \\
\hline \multirow{2}{*}{$\begin{array}{l}\text { Chronic condition } \\
\text { No }\end{array}$} & & $\begin{array}{l}68 \\
(46.3 \%)\end{array}$ & $\begin{array}{l}274 \\
(80.1 \%)\end{array}$ & \\
\hline & & $\begin{array}{l}79 \\
(53.7 \%)\end{array}$ & \multirow[t]{2}{*}{$68(19.9 \%)$} & \\
\hline & & $\begin{array}{l}84 \\
(57.1 \%)\end{array}$ & & \\
\hline & & $\begin{array}{l}63 \\
(42.9 \%)\end{array}$ & & \\
\hline
\end{tabular}


Table 4

Probability of hospitalization under National Health Insurance (NHI) scheme

\begin{tabular}{|c|c|c|c|c|}
\hline \multirow{4}{*}{$\begin{array}{l}\text { Independent variable } \\
\text { (based on Andersen's Behavioral } \\
\text { Model) }\end{array}$} & \multicolumn{4}{|c|}{$\begin{array}{l}\text { Binary logistic regression model 1:probalbity of } \\
\text { hospitalization }\end{array}$} \\
\hline & \multicolumn{2}{|c|}{ NHI 2018} & \multicolumn{2}{|c|}{ NHI 2021* } \\
\hline & \multicolumn{2}{|c|}{ Nagelkerke $\mathrm{R}^{2}=0.248$} & \multicolumn{2}{|c|}{ Nagelkerke $R^{2}=0.411$} \\
\hline & OR & P-value & OR & P-value \\
\hline Predisposing factors & 0.882 & 0.815 & 0.992 & 0.976 \\
\hline Gender of respondent & 1.524 & 0.357 & 0.518 & 0.125 \\
\hline Male & 2 & 0.648 & 9.763 & $0.001 *$ \\
\hline Female & 3.610 & $0.050^{*}$ & 1.104 & 0.737 \\
\hline Age of respondent & 1.371 & 0.150 & - & - \\
\hline $18-35$ & 3.205 & 0.188 & -- & - \\
\hline $36-69$ & - & - & 1.330 & 0.531 \\
\hline 50 or above & - & - & 0.803 & 0.656 \\
\hline Marital status & 5.128 & $0.02 *$ & 0.766 & 0.371 \\
\hline Single & 0.516 & $0.037^{\star}$ & - & - \\
\hline Married & 0.135 & 0.08 & -- & - \\
\hline Level of education (2018 study) & - & - & 0.793 & 0.584 \\
\hline Never attended school & - & - & 0.924 & 0.831 \\
\hline Primary school & - & - & 1.024 & 0.958 \\
\hline Lower secondary or higher & - & - & 0.833 & 0.519 \\
\hline Level of education (2021 study) & 0.960 & 0.935 & 1.716 & 0.163 \\
\hline \multicolumn{5}{|l|}{$\begin{array}{l}\text { Never attended school to Primary } \\
\text { school }\end{array}$} \\
\hline \multicolumn{5}{|c|}{ Lower secondary to Secondary school } \\
\hline \multicolumn{5}{|l|}{ College/ university degree } \\
\hline \multicolumn{5}{|l|}{ Size of household } \\
\hline \multicolumn{5}{|l|}{ 1-4 people (small) } \\
\hline \multicolumn{5}{|l|}{5 people or more (large) } \\
\hline Enabling factors & & & & \\
\hline
\end{tabular}




\begin{tabular}{|c|c|c|c|c|}
\hline \multirow{4}{*}{$\begin{array}{l}\text { Independent variable } \\
\text { (based on Andersen's Behavioral } \\
\text { Model) }\end{array}$} & \multicolumn{4}{|c|}{$\begin{array}{l}\text { Binary logistic regression model 1:probalbity of } \\
\text { hospitalization }\end{array}$} \\
\hline & \multicolumn{2}{|c|}{ NHI 2018} & \multicolumn{2}{|c|}{ NHI 2021* } \\
\hline & \multicolumn{2}{|c|}{ Nagelkerke $\mathrm{R}^{2}=0.248$} & \multicolumn{2}{|c|}{ Nagelkerke $\mathrm{R}^{2}=0.411$} \\
\hline & OR & P-value & OR & P-value \\
\hline \multicolumn{5}{|l|}{ Level of income (2018 study) } \\
\hline \multicolumn{5}{|l|}{ Less than 1 million LAK (US\$100) } \\
\hline \multicolumn{5}{|l|}{$\begin{array}{l}1-2.5 \text { million LAK (US\$100 - } \\
\text { US\$250) }\end{array}$} \\
\hline \multicolumn{5}{|l|}{2.5 million LAK (US\$300) or more } \\
\hline \multicolumn{5}{|l|}{ Level of income (2021 study) } \\
\hline \multicolumn{5}{|l|}{ Less than 1 million LAK (US\$100) } \\
\hline \multicolumn{5}{|l|}{$\begin{array}{l}1-2.5 \text { million LAK (US\$100 - } \\
\text { US\$250) }\end{array}$} \\
\hline \multicolumn{5}{|l|}{$\begin{array}{l}2.5-5 \text { million LAK (US\$250 - US\$ } \\
500)\end{array}$} \\
\hline \multicolumn{5}{|l|}{ More than 5 million LAK (US\$ 500) } \\
\hline \multicolumn{5}{|l|}{ City of residence } \\
\hline \multicolumn{5}{|l|}{ Capital (Kaysone Phomvihane district) } \\
\hline \multicolumn{5}{|l|}{ Others districts } \\
\hline \multicolumn{5}{|l|}{ Need factors } \\
\hline \multicolumn{5}{|l|}{ Chronic condition } \\
\hline \multicolumn{5}{|l|}{ No } \\
\hline Yes & & & & \\
\hline
\end{tabular}


Table 5

Probability of entering to catastrophic health expenditure under National Health Insurance (NHI) scheme

Independent variable
(based on Andersen's Behavioral
Model)

Binary logistic regression model 1:probalbity of catastrophic health expenditure

Model)

NHI 2018

NHI 2021*

-

Predisposing factors

Gender of respondent

Male

Female

Age of respondent

18-35

36-69

50 or above

Marital status

Single

Married

Level of education (2018 study)

Never attended school

Primary school

Lower secondary or higher

Level of education (2021 study)

Never attended school to

Primary school

Lower secondary to Secondary

school

College/ university degree

Size of household

1-4 people (small)

5 people or more (large)

Enabling factors
0.662

1.223

0.803

0.643

0.943

1.156

0.792

$-$

$-$

0.946

1.166

1.117

0.211

0.457

0.144

0.505

$-$

$-$

0.836

0.894

0.900

-

0.224

0.021

0.005

3.766

107.908

0.755

0.269

0.228

0.000 *

\section{P-value}

0.782

0.065

0.481

0.352

0.001 *

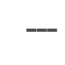

$-$

0.004 *

$0.001^{*}$

0.001 *

0.001 *

0.001 * 


\begin{tabular}{|c|c|c|c|c|}
\hline \multirow{4}{*}{$\begin{array}{l}\text { Independent variable } \\
\text { (based on Andersen's Behavioral } \\
\text { Model) }\end{array}$} & \multicolumn{4}{|c|}{$\begin{array}{l}\text { Binary logistic regression model 1:probalbity of catastrophic } \\
\text { health expenditure }\end{array}$} \\
\hline & \multicolumn{2}{|c|}{ NHI 2018} & \multicolumn{2}{|c|}{ NHI 2021* } \\
\hline & \multicolumn{2}{|c|}{ Nagelkerke $R^{2}=0.301$} & \multicolumn{2}{|c|}{ Nagelkerke $R^{2}=0.703$} \\
\hline & OR & P-value & OR & P-value \\
\hline \multicolumn{5}{|l|}{ Level of income (2018 study) } \\
\hline \multicolumn{5}{|l|}{$\begin{array}{l}\text { Less than } 1 \text { million LAK } \\
\text { (US\$100) }\end{array}$} \\
\hline \multicolumn{5}{|l|}{$\begin{array}{l}1-2.5 \text { million LAK (US\$100 - } \\
\text { US\$250) }\end{array}$} \\
\hline \multicolumn{5}{|l|}{$\begin{array}{l}2.5 \text { million LAK (US\$300) or } \\
\text { more }\end{array}$} \\
\hline \multicolumn{5}{|l|}{ Level of income (2021 study) } \\
\hline \multicolumn{5}{|l|}{$\begin{array}{l}\text { Less than } 1 \text { million LAK } \\
\text { (US\$100) }\end{array}$} \\
\hline \multicolumn{5}{|l|}{$\begin{array}{l}1-2.5 \text { million LAK (US\$100 - } \\
\text { US\$250) }\end{array}$} \\
\hline \multicolumn{5}{|l|}{$\begin{array}{l}2.5-5 \text { million LAK (US\$250 - } \\
\text { US\$ 500) }\end{array}$} \\
\hline \multicolumn{5}{|l|}{$\begin{array}{l}\text { More than } 5 \text { million LAK (US\$ } \\
500 \text { ) }\end{array}$} \\
\hline \multicolumn{5}{|l|}{ City of residence } \\
\hline \multicolumn{5}{|l|}{$\begin{array}{l}\text { Capital (Kaysone Phomvihane } \\
\text { district) }\end{array}$} \\
\hline \multicolumn{5}{|l|}{ Others districts } \\
\hline \multicolumn{5}{|l|}{ Need factors } \\
\hline \multicolumn{5}{|l|}{ Chronic condition } \\
\hline \multicolumn{5}{|l|}{ No } \\
\hline Yes & & & & \\
\hline
\end{tabular}

Source: Social Health Protection Network ${ }^{2}$

Several studies were conducted to assess $\mathrm{CBHI}$ and $\mathrm{NHI}$ 's impact on their effectiveness and improvement on accessibility and financial protection against catastrophic health expenditures. The results of these previous studies reveal that $\mathrm{CBHI}$ significantly improves access to health service utilization for households with chronic conditions. Most insured households under the $\mathrm{CBHI}$ scheme were able to avoid financial catastrophe due to health service utilization. However, poor households still retained the highest 
probability of entering catastrophic health expenditures related to health service utilization ${ }^{1,4}$. As a voluntary health financing scheme, members were required to pay membership or contribution rates. As there was no medical check before enrolling in the system, households' existing chronic conditions strongly affected health service utilization. In other words, households with a chronic illness or health problem are more likely to enroll or acquire health insurance ${ }^{5}$. Under the NHI's coverage, the benefits package provides most health service in public/ government health care facilities. Few exceptions correspond to health services, such as VIP rooms, medicines not categorized in the essential medicine list, and traffic and work accidents. Services under the coverage of other vertical projects (AIDS, tuberculosis, and malaria) and non-essential services (plastic surgery, detail care, and other services) are not included in the NHI's coverage. Unlike its predecessor, under the coverage of $\mathrm{NHI}$, patients or their households are required to pay $25 \%$ (as a co-payment) for health services exceeding LAK 5 million (US\$ 500). The introduction of $\mathrm{NHI}$ immensely increases the effectiveness of health service utilization for households in poorest income groups. Without a monthly or yearly contribution rate as the CBH scheme, there was a massive increase in hospital visits. As a result, without physical hospitals' physical expansion, health facilities become crowded and overutilized, with long waiting times, and were overloaded. As a result, the majority of patients in the top income quintiles opt to seek treatment in neighboring countries (in the notion that they will receive better health care) ${ }^{2,6}$.

Chronic Kidney Disease (CKD) is increasingly becoming a global public health problem, which disproportionately burdens low and middle countries, where detection and diagnostic rate remain low, with an approximate overall prevalence of $8-16 \%{ }^{7}$. This corresponds to almost 500 million individuals with kidney-related health issues, in which more than $78 \%$, or nearly 390 million people, resides in low and middle-income countries ${ }^{8}$. In particular, the mortality rate attributable to CKD between 1990 and 2010 has almost doubled, escalating to the 18th leading cause of mortality in $2012^{9}$. Regardless of the fact that the exact public health burden of CKD in lower and middle income has not been carefully elucidated, the previous study has found that the incidence rate could be four times more than those observed in developed countries ${ }^{7}$.

Hemodialysis (HD) was initially included in the voluntary-based $\mathrm{CBH}$ scheme. It has been under the coverage of $\mathrm{NHI}$ since its introduction. However, only five HD sessions are under the coverage of the NHI. After the fifth HD session, patients or their families are expected to pay US\$55-US\$60 per session in outpocket-expenditure. Laos is still in the initial stage for the development of Continuous Ambulatory Peritoneal Dialysis (CAPD). Human resources (dietitians or clinical engineers) are still in shortage, as most Lao patients prefer to go to neighboring countries for health service utilization. End State Renal Disease (ESRD) patients are not an exception; most Lao patients seek their first HD in Thailand and Vietnam, then those patients come back and receive maintenance HD locally ${ }^{10}$. NHI in Savannakhet provinces devised a policy that covers unlimited HD sessions in order to increase accessibility and avoid financial disasters that may have happened after the fifth HD session. Under this policy, patients are expected to pay as low as the IPD flat rate of LAK 30,000 (US\$3) for each HD session. The HD session is provided only at Savannakhet Provincial Hospital and 109 Hospital in Outhoumphone district, where the 
first hospital has thirteen HD machines and the second hospital has one HD machine. However, only HD sessions at Savannakhet Provincial hospital in Kaysone Phomvihane district are under the NHI's coverage. In terms of operation, the HD machines operate from Monday to Friday; each machine is in charge of two HD sessions daily. In other words, the Savannakhet Provincial Hospital could hold up to 26 patients on a daily basis. Undoubtedly, with more government subsidies, this policy enhances accessibility and financial protection for patients and their households. However, without physical expansion, the hospital could end up being overloaded with a longer waiting time. Without the Covid-19 travel restriction, wealthier households prefer to seek health service utilization in private hospitals, hospitals in other provinces, and neighboring countries, predominantly Thailand and Vietnam

Regardless of the $\mathrm{NHI}$ coverage, there is a possibility for patients and their households to encounter catastrophic health expenditures due to non-medical spending. Catastrophic health expenditure or financial catastrophe is a situation where patients' health expenditure needs to pay or copay more than or equal to $40 \%$ of non-subsistence income their households ${ }^{11}$. In many cases, a patient must seek an organ transplant to improve their quality of living. Since medical services in Laos do not offer organ transplants, patients have sought organ transplants in neighboring countries using out-of-pocket expenditure when needed. The limited number of organ donors and health service utilization costs prevent most patients from accessing organ transplants. This study aims to carefully analyze the role of Laos' National Health Insurance on accessibility and the possibility of encountering catastrophic health expenditure for chronic kidney disease patients. In addition, this study is also willing to provide policy recommendations for policymakers in promoting the coverage of organ transplantation under $\mathrm{NHI}$ in the future.

\section{Methodology}

\section{Research Design}

This study applies a cross-sectional survey designed to assess the roles and impact of $\mathrm{NHI}$ on providing accessibility and financial protection against catastrophic health expenditure for patients and their households suffering from Chronic Kidney Disease. The Andersen's Behavioral Model serves as a guide for the analytical process in this research. The model is divided into three components, which are as follows: predisposing, enabling, and needs-based characteristics. ${ }^{12}$.

The findings were compared to those of a comparable study conducted in Savannakhet province, which sought to determine the influence of the $\mathrm{NHI}$ on health care accessibility and financial protection against catastrophic health spending 6 .

\section{Data Collection}

The Savannakhet Province was purposively selected as a study site. It should be recalled that the HD session is only available at the Savannakhet Provincial Hospital. This hospital has been used as a focal point of this research. The data collection sessions were conducted through face-to-face and VDO 
conferences using a structured questionnaire, from January to early April 2021, before the second lockdown due to the Covid-19 outbreak had taken place. In the first wave of the Covid-19 (early 2020), Laos avoided a significant health crisis with relatively low reported numbers of inflected people, at as low as 49 cases from March 2020 to March $2021^{13}$. As a result, some interview sessions were implemented at the Savannakhet Provincial Hospital. This study interviews 342 cases, in order to have comparable sample sizes with the survey conducted in $2018^{6}$. As patients generally register on a waiting list prior to getting health services, the data gathering team randomly picked respondents from the waiting lists. The interviews were conducted prior to or after the receipt of health care. The interview team may also use VDO conferences as an alternative for responses and for convenience. Moreover, additional information has been retrieved by interview sessions from key informants that includes nurses, and healthcare personnel in Savannakhet provinces. Additional information was gathered via in-depth interviews with key informants, such as nurses, medical doctors, NHI staff, and healthcare staff from Savannakhet provinces.

\section{Statistical Analysis and Interpretation}

Descriptive statistical analysis has been used to present cross-tabulation information of respondents and/or their households' sociodemographic characteristics and hospital admission/ Inpatient Department (IPD). On the other hand, the logistic regression model had been used to analyze the probability of healthcare services utilization and financial catastrophe due to health service expenditure.

This study assumes that the probability of hospitalization is the proxy of accessibility to health service utilization. Since the data collection process was carried out at the hospital, all respondents would report receiving health service utilization. In this regard, the researcher team attempted to avoid such bias by ignoring the time at the hospital during the interview. Respondents were obliged to give information regarding their use of IPD health services in the past 12 months during the interview session.

In the analytical process, the dependent variables for logistic regression models are the likelihood of hospitalization (model 1 ) and the probability of experiencing catastrophic health expenditure (model 2). On the other hand, the independent variables have been derived from the Andersen's Behavioral Model, which composes of predisposing factors (gender, age, marital status, level of education, and size of household), enabling factors (household's income level and city of residence), and need factors (chronic condition within the household).

Validity

The researcher team applies construct validity to ensure that a theoretical foundation has supported the study's conceptual framework. The process includes utilizing various sources of information, creating a chain of evidence, and key informant reviews. Before circulating the questionnaire to the data collection team, external experts carefully check content validity to ensure that the structured questionnaire covers all details used in the manuscript writing process ${ }^{14}$. 


\section{Funding}

RachadapisaekSompot Fund of the Graduate School, Chulalongkorn University is the main sponsor of this research.

\section{Results}

The descriptive information of 342 respondent/ household characteristics on hospital admission and catastrophic health expenditure are presented in table 2 and table 3 , respectively. The sociodemographic characteristics include gender of respondents, marital status, age of respondents, level of education, size of household, level of income, occupation, city of residence, and chronic conditions.

As shown in Table 2, the HD session under the $\mathrm{NHI}$ is only available at the Savannakhet Provincial Hospital in KaysonePhomvihane District. Patients who resided in other 14 districts need to travel to KaysonePhomvihane for treatments. In this regard, the city of residence has been divided into two categories: the KaysonePhomvihane District, capital of the Savannakhet Province, and other districts within the provinces. According to the Pearson $\mathrm{X}^{2}$ value, it has been observed that only the "age of respondent" is statistically significant at a $95 \%$ confidence interval. In particular, most of the respondents aged more than 50 years old at 123 counts (81.5\%), followed respondents aged between 36-49 years and $18-35$ years old at $15(9.9 \%)$ and $14(8.6 \%)$, respectively. This statement means that the relationship between the "age of respondents" and hospital admission is not independent.

Table 3 shows the crosstabulation statistics between respondents'/ households' characteristics and catastrophic health expenditure due to health service utilization. This study assessed catastrophic health expenditure based on medical and non-medical expenses related to IPD sessions. The data shows that 147 households out of 342 samples suffered from financial catastrophe due to health-related spending. At a 95\% confidence level, five factors in Table 3 are statistically significant: level of education, level of income, respondent's employment, city of residence, and presence of chronic conditions within households. Each of these factors is not independent of a household's financial catastrophe when the Pearson $\mathrm{X}^{2}$ score is less than 0.05 .

The comparison between the probability of hospitalization under the protection of NHI in 2018 and 2021 has been presented in Table 4. The independent variables of both studies were based on Andersen' Behavioral Model. Due to the context of the studies, the details of variables are slightly different such as level of education and level of income. In addition, city of residence of patients who seeks for HD session has been included as a variable under the enabling factors.

The logistic regression (model 1) presented in Table 4 shows that only respondents aged more than 50 years old are 9.763 times more likely to use IPD service when compared to respondents aged between 18 to 35 years old at a $95 \%$ confident interval. Regardless of not being statistically significant, households with chronic conditions and kidney issues are 1.716 times more likely to be hospitalized. The outcome of the logistic regression is distinct from the previous research (in 2018), which estimated the likelihood of 
hospitalization under $\mathrm{NHI}$ for general patients using data from the respondent's various target groups. The previous research demonstrated that marital status, home size, and income levels were statistically significant. The pseudo $\mathrm{R}^{2}$, or also known as Nagelkerke $\mathrm{R}^{2}$ values, have also been presented to estimate the goodness-of-fit of each model. The pseudo $\mathrm{R}^{2}$ under $\mathrm{NHI}$ in 2021 is higher - with the value of 0.411 , compared to the previous study in 2018 , where the value was observed at 0.248 . This value means that independent variables account for $41.1 \%$ of reasons for using health service utilization.

As shown in table 5, the logistic regression Model 2 estimates the catastrophic health expenditure of patients at the HD section at the Savannakhet Provincial Hospital.Assessments of catastrophic health expenditure conditions within a household have been made using the household's annual income and health spending over the preceding 12 months. Households with total health expenses (including nonmedical and medical) over $40 \%$ of annual revenue were determined to have catastrophic health expenditures. This logistic regression model found that five independent variables were statistically significant: level of education, size of household, level of income, city of residence, and chronic conditions. Firstly, in terms of education, the respondent with the lowest education background has 3.717 (invert $O R=1 / 0.269$ ) times higher the chance of incurring catastrophic health expenditure, when compared to respondents with "lower secondary school to secondary school" background. The invert OR also found that small households with 1-4 members have 4.464 (Invert $O R=1 / 0.228$ ) times the higher possibility of financial hardships than larger households (more than 5 members). Undoubtedly, income level is an essential factor in assessing the likelihood of catastrophic health expenditure; the outcome shows that all income quantiles were statistically significant. In particular, households categorized in the lowest income quantile with a monthly income of less than 1 million LAK (US\$100) have approximately 200 times (invert $O R=1 / 0.005$ ) higher probability of encountering catastrophic health expenditure, when compared to the wealthiest income quantile. As HD session is only available at the Savannakhet Provincial Hospital, in the KaysonePhomvihane District. In this regard, it is assumed that people who resided in KaysonePhomvihane District are more likely to have less non-medical expenditures when compared to patients from far-away districts. The logistic regression model shows that patients from other districts were 3.766 times more likely to end up with catastrophic health expenditure when compared to patients who resided in the KaysonePhomvihane District. The situation is observed to be even worse for households with the existence of additional chronic condition; the model shows that households with chronic conditions are estimated to be almost 108 times more likely to incur healthrelated financial catastrophe when compared to a household without other chronic conditions. In 2018, model 2 discovered that households with chronic diseases had an approximately 8.695 greater likelihood of having catastrophic health expenditure. In terms of pseudo $R^{2}$ values, the likelihood of catastrophic health spending associated with HD sessions is greater than the likelihood of catastrophic health expenditure associated with other health issues.

\section{Discussion}


As a pilot project, $\mathrm{NHI}$ now covers unlimited HD sessions in many provinces, including Savannakhet Province. However, the dialysis machine is only available in the KaysonePhomvihane District, the capital of Savannakhet Province. As a result, there is a barrier to accessing health services, as well as financial hardships due to non-medical expenditures. Only respondents' ages were found to be statistically significant in the regression model 1, implying that the $\mathrm{NHI}$ scheme can increase health service consumption equally for all determinants except ages. The initiative, in particular, increases access to health care for households with chronic kidney disease, regardless of the city in which they live and their income level. According to Table 2, it can also be observed that $38 \%$ of respondents reported having a household monthly income between 2.5 - 5 million LAK (US\$250 - US\$500); in other groups, this percentage varied between $19.6 \%$ to $21.9 \%$. Approximately $41.5 \%$ of patients come from other districts for the city of residence, which means that people residing in other districts do not have any problem accessing HD sessions or IPD services in a provincial hospital. A case study in Cambodia shows that financial issue is the most crucial factor preventing access to health services at HD centers. With an average income of US\$150 per month in Phnom Penh, Cambodia, the HD costs are ranged from US\$45 to US\$60 per session. As the health insurance system does not cover it, patients are expected to be responsible for all medical costs themselves, known as out-of-pocket expenditure. Hence, it is said that the HD session is only available for upper classes households ${ }^{10}$.

In Indonesia, a health financing program is critical for providing access to and financial protection against catastrophic health expenditures for a household with renal problems. The Indonesian government formed the Healthcare and Social Security Agency in 2013 (known as Badan PenyelenggaraJaminanSosialKesehatan or "BPJS Kesehatan").It is nationally required for employees to contribute to this health care scheme. As a steppingstone toward universal coverage, all residents (including long-term expatriates) are required to join. Also, in exchange for family coverage, one spouse must make a payment to the scheme for the family to be covered. The BPJS scheme also offers total coverage for dialysis treatment, which eases the accessibility to health service utilization for End-Stage Renal Disease (ESRD) ${ }^{15}$. As of 2014, the BPJS revealed that chronic kidney disease became the second leading cause of morbidity after heart disease. The BPSJ's payment for the coverage of kidney patients was more than US\$161 million ${ }^{16}$.In Thailand's scenario, the government has made an effort to improve accessibility for patients with kidney ailments. Since 2003, the Social Security System (SSS) has covered dialysis as a health care. Although the Universal Healthcare Coverage Scheme (UCS) was implemented in 2002, it did not include Renal Replacement Therapy (RRT) until $20088^{17,18 .}$

Logistic regression Model 2 found that many factors can lead respondents/ their households to financial hardship. Most significantly, chronic conditions, in addition to kidney issues, dramatically increase the chance of suffering catastrophic health expenditures. In recent years, Multiple Chronic Conditions (MCC) have continuously proliferated among individuals of all ages. These health issues are highly associated with health utilization and cost implication for individuals, families, insurance payers, and public sectors. The result of the previous study found that the average per-capital health service costs of patients with 2 , 3 , and more than four chronic conditions have been increased to $107.4 \%, 307.4 \%$, and $1110.8 \%$, in 
comparison to patients with a single chronic illness ${ }^{19}$. A study in China found that patients with more chronic diseases significantly had higher treatment costs when compared to those with a single disease. Specifically, patients with four chronic diseases usually had about three times higher out-of-pocket expenditures when compared to patients without chronic health issues ${ }^{20}$. City or location of residence is also an essential factor that leads to catastrophic health expenditure. There are 15 districts in the Savannakhet Province; some patients need to travel more than 3 hours to receive HD sessions in the KaysonePhomvihane District. Longer distance traveled directly increases non-medical expenditures related to health services. In this case, non-medical expenses refer to transportation, accommodations, and other accompanied household members' expenditures. Most of the wealthy households in Laos prefer to use health service utilization in neighboring countries in the ASEAN region, such as Thailand, Vietnam, and Singapore ${ }^{21}$. The overseas health services include HD sessions, renal replacement therapy, and other organ transplants. However, most recently, access to health services in a foreign country has become very difficult due to the travel restriction in the Covid 19 pandemic. This situation consequently leads to greater numbers of patients in referral hospitals and other local health facilities. As a result, patients need to spend more time waiting for HD sessions. Several individuals decided to seek health care in Vientiane, the capital, on their own expense, despite the fact that they would have to travel almost 485 kilometers. This practice proportionally creates more expenses for the households and increases the likelihood of experiencing catastrophic health expenditures.

By making a comparison between the NHI's impact on preventing catastrophic health expenditures for general patients and patients with chronic kidney health issues, it is proven that the $\mathrm{NHI}$ scheme is effectively able to protect households from suffering catastrophic health expenditure. In contrast, households categorized in the lowest income quintile (with a monthly income of US\$100) are significantly associated with the highest possibility of suffering from health-related financial catastrophe. The result is in tandem with the previous research, which has revealed that Lao patients cannot access $\mathrm{HD}$ regularly due to financial constraints ${ }^{10}$. In this regard, many patients in the rural areas who reside far away from referral hospitals prefer to use alternative

\section{Conclusion And Policy Recommendations}

The regression models have been used to examine accessibility and financial protection against catastrophic health expenditures associated with surveyed patients' chronic kidney disease. In terms of accessibility, as age is the only statically significant variable, this means that the $\mathrm{NHI}$ equally distributed accessibility for all households regardless of their social-economic status. In addition, the result of this study is comparable with the previous study conducted in 2018, which aimed to assess accessibility for health service utilization for general patients. On the other hand, the second regression model observed many different outcomes when compared chronic kidney patients, general patients, at the Outpatient Department (OPD_, in which the factors led to financial difficulties and catastrophic health expenditure includes the level of education, size of households, level of income, city of residence, and additional chronic conditions within households. In this regard, studies in 2018 and 2021 concluded that the NHI 
scheme effectively protects households from catastrophic health expenditures without any chronic health issues. Non-medical spending is the main factor that creates huge expenses and finally leads to poverty.

Concerning the study outcome, several policy recommendations have been provided for policymakers to enhance the effectiveness of the NHI. Firstly, regarding the fact that the HD sessions are only available at a referral hospital (Savannakhet Provincials Hospital). It is necessary for the government to provide more medical equipment (dialysis equipment). In addition, there is a considerable demand for more dialysis nurses, nephrologists, laboratories, and infrastructure for HD therapy. This is because improved infrastructure will consequently lower non-medical expenditures, helping people who would suffer from catastrophic health expenditures.

For chronic kidney disease, an HD session may not be the end of the road for treatment. Large numbers of patients in Laos seek renal transplants in neighboring countries, predominantly Thailand and Vietnam. The patients receive organs through their personal connections, such as families and relatives. In the short run, NHI's policymakers are highly recommended to collaborate with neighboring countries' hospitals (Thailand and Vietnam), which allow accessibility for Lao patients to access health services through the copayment mean.

Thailand's first organ transplant was a kidney transplant surgery at Chulalongkorn Hospital, back in 1974. Liver and heart transplants were performed 30 years later. The accessibility to organ transplants was very limited and restricted by high expenditure. As a result, most of the patients receiving the transplants were civil servants and those in wealthy families. In 2007, The National Health Security Office (NHSO) approved kidney replacement therapy benefits for end-stage renal failure patients, including kidney transplantation. Later, liver and heart transplants are also supported in cooperation with the Thai Red Cross Society, for organ donation. The target donors are patients who are in a brain-dead state. Thailand is developing organ transplant centers. There are currently thirty kidney transplant centers, ten liver transplant centers, and five heart transplant centers, resulting in all Thai people having access to transplantation ${ }^{22}$. The kidney transplant cost at the Thai public hospital is between 200,000 to 250,000 THB (US\$6,136 to US\$ 7,671). The expenditure could increase to approximately 300,000 to 350,000 THB for patients with other complications. The expenses for a kidney transplant at private hospitals usually costs more than three times higher than at public hospitals, starting from 700,000 THB to $1,000,000$ THB (US\$21,478 - US\$30,700) if there is some complication during the transplant process ${ }^{23}$. For the longterm policy recommendations, the government should move forward to include kidney transplants in the NHI's health care system. As the cost for a kidney transplant in Laos will be comparable to Thai public hospitals, in the beginning, the NHI policymakers may apply copayment or payment plans for patients. Moreover, the government needs to increase the supply of laboratories, transplant surgeons and nurses, and consider the establishment of a renal bank for transplant surgery.

\section{Abbreviations}

- $\mathrm{CAPD}=$ Continuous Ambulatory Peritoneal Dialysis; 
- $\mathrm{CBHI}=$ Community-Based Health Insurance;

- $\mathrm{CKD}=$ Chronic Kidney Disease;

- ESRD = End State Renal Disease;

- $F M N C H=$ Free Maternal Neonatal and Child Health;

- $\mathrm{HD}=$ Hemodialysis;

- HEF = Health Equity Fund;

- IPD =Inpatient Department;

- $\mathrm{MCC}=$ Multiple Chronic Conditions;

- $\mathrm{NHI}=$ National Health Insurance;

- $\mathrm{NHSO}=$ National Health Security Office;

- OPD = Outpatient department;

- OR = Odd Ratio;

- RRT = Renal Replacement Therapy;

- SASS = State Authority for Social Security;

- SSO = Social Security Organization Scheme;

- SSS = Social Security System;

- $\mathrm{UCS}=$ Universal Healthcare Coverage Scheme .

\section{Declarations}

\section{Ethics approval and consent to participate}

- The authors obtained ethical approval from National Ethics Committee for Health Research (NECHR), National Institute of Public Health, Ministry of Health

\section{Consent for publication}

- Both authors: Somdeth Bodhisane, Ph.D. and Prof. SathirakornPongpanich, Ph.D. have consensually agreed to publish the manuscript entitled"the influence of the National Health Insurance on access and catastrophic health expenditures for patients with chronic renal disease; and the possibility of integrating organ transplantation in Laos' health financing system"

Availability of data and materials (available upon request).

- Information for respondents and informed consent 
- Questionnaire for respondents

- SPSS data base

Competing interests

- Both authors declare that there is no competing interest in this research

\section{Funding}

- RachadapisaekSompot fund of Graduate School, Chulalongkorn University is supporter of this research.

Authors' contributions

- Somdeth Bodhisane, Ph.D. is responsible for designing the questionnaire, conducting the field survey and data collection, statistical analysis, and drafting the manuscript

- SathirakornPongpanich, Ph.D. is responsible for drafting the research design and researchmethodology, and finalizing the manuscript

Acknowledgements

- This research could not be completed without the support from Professor SathirakornPongpanich, the co-author, who is the dean of the College of Public Health Science (CPHS). I would like to show my gratitude to officers in Savannakhet Department of Health and Savannakhet Provincial hospital for their assistance, advice, and recommendation during the data collection process. I also want to take this opportunity to express my sincere thanks to the RachadapisaekSompote Fund of Graduate School, Chulalongkorn University, for financial support throughout the research.

\section{References}

1. Bodhisane S, Pongpanich S. The Impact of Community Based Health Insurance in Enhancing Better Accessibility and Lowering the Chance of Having Financial Catastrophe Due to Health Service Utilization: A Case Study of Savannakhet Province, Laos. International Journal of Health Services. 2015;47(47):504-518.

2. SHPN. National UNC dynamics card Laos. https://p4h.world/en/national_uhc_dynamics_card_laos. Published 2021. Accessed.

3. WHO. Overview of Lao Health System Development 2009-2017. World Health Organization - Western Pacific Region; 2018.

4. Bodhisane S, Pongpanich S. Community based health insurance: A case study. Community based health insurance: A case study. 2017;23(2).

5. Cutler D, Zeckhauser R. Adverse selection in health insurance. Cambridge, MA: National Bureau of Economic Research 1997. 
6. Bodhisane S, Pongpanich S. The impact of National Health Insurance upon accessibility of health services and financial protection from catastrophic health expenditure: a case study of Savannakhet province, the Lao People's Democratic Republic. Health Research Policy and Systems. 2019;17(99).

7. George C, Mogueo A, Okpechi I, Echouffo-Tcheugui J, Kengne A. Chronic kidney disease in lowincome to middle-income countries: the case for increased screening. BMJ Glob Health 2017(2).

8. Mills K, Xu Y, Zhang W, et al. A systematic analysis of world-wide population-based data on the global burden of chronic kidney disease in 2010. Kidney Int. 2015.

9. Lozano R, Naghavi M, Foreman K, et al. Global and regional mortality from 235 causes of death for 20 age groups in 1990 and 2010: a systematic analysis for the Global Burden of Disease Study 2010. Lancet. 2012;380(9859):2095-2128.

10. Hyodo T, Fukagawa M, Hirawa N, et al. Present status of renal replacement therapy in Asian countries as of 2016: Cambodia, Laos, Mongolia, Bhutan, and Indonesia. Renal Replacement Therapy. 2019;5(1):12.

11. Kawabata K, Xu K, Carrin G. Preventing impoverishment through protection against catastrophic health expenditure. Bull World Health Organ. 2002;80(8):612.

12. Wolinsky F. Assessing the effects of the physical psychological, and social dimensions of health on the use of health services. The Sociological Quarterly. 1982;23:191-206.

13. Onphanhdala P. The economic impact of the second Covid-19 outbreak in Laos. Vientiane Capital, Laos 2021.

14. Mugenda A, Mugenda O. Research Methods: Qualitative and quantitative approaches. Nairobi: ACTS Press; 1999.

15. KPMG. BPJS Kesehatan: A new medicare system? IES BUllentin. 2014.

16. Trisnantoro L, Jasri H, Rahman PA. Prevention and Law Enforcement System of Fraud in Health Services. Jakarta: Center of Health Policy and Management Faculty of Medicine University of Gadjah Madan Yogyakarta; 2014.

17. SSO. Announcement of the Medical Committee under the Social Security Act Regarding the criteria and rates for compensation benefits in case of kidney replacement therapy 2005.

18. Chuengsaman P, Kasemsup V. PD First Policy: Thailand's Response to the Challenge of Meeting the Needs of Patients With End-Stage Renal Disease. Semin Nephrol. 2017;37(3):287-295.

19. Wolff JL, Starfield B, Anderson G. Prevalence, expenditures, and complications of multiple chronic conditions in the elderly. Arch Intern Med. 2002;162(20):2269-2276.

20. Zhao Y, Atun R, Anindya K, et al. Medical costs and out-of-pocket expenditures associated with multimorbidity in China: quantile regression analysis. BMJ Global Health. 2021;6(2):e004042.

21. Bodhisane S, Pongpanich S. The accessibility and probability of encountering catastrophic health expenditure by Lao patients in Thai hospitals. J Public Health (Oxf). 2021.

22. WHR. Laos - Kidney disease. World Health Ranking. https://www.worldlifeexpectancy.com/laoskidney-disease. Published 2021. Accessed November 19, 2021. 
23. Areesantichai C, Perngparn U, Supakankunti S. Medical Service Value Project To define a list of main benefit packages and supplementary benefits packages in the public health insurance system on organ transplant. Bangkok, Thailand: College of Public Health Science;2020. 